\title{
Experimental study of a new tracheal prosthesis: Pored Dacron tube
}

\author{
Hisashi Tsukada, MD \\ Hiroaki Osada, MD, PhD
}

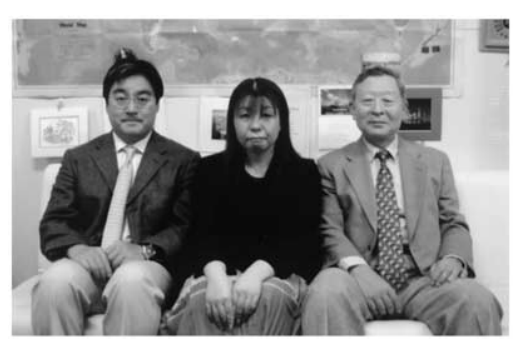

Left to right: Tsukada, Tanaka, Osada
From the St Marianna University School of Medicine, Department of Surgery, Division of Chest Surgery, Kawasaki, Japan.

Received for publication April 14, 2003; revisions requested June 12, 2003; revisions received June 26, 2003; accepted for publication July 17, 2003.

Address for reprints: Hisashi Tsukada, MD, St Marianna University School of Medicine, Department of Surgery, Division of Chest Surgery, 2-16-1 Sugao Miyamae-ku, Kawasaki, Japan (E-mail: h2tukada@ marianna-u.ac.jp).

J Thorac Cardiovasc Surg 2004;127:877-84 $0022-5223 / \$ 30.00$

Copyright ( $(2) 2004$ by The American Association for Thoracic Surgery

doi:10.1016/S0022-5223(03)01317-5
Objective: This study was designed to evaluate how various sizes and densities of pores in Dacron tubing might enhance its utility as a tracheal prosthesis.

Methods: A vascular prosthesis made of knitted external velour polyester was prepared for pore formation with a laser. The first set compared different pore sizes $(300,500$, and $700 \mu \mathrm{m})$ and pore densities $\left(25 / \mathrm{cm}^{2}\right.$ or $\left.100 / \mathrm{cm}^{2}\right)$. Grafts were reinforced with an externally heat-sealed silicone ring. The second set tested grafts with a pore density of $64 / \mathrm{cm}^{2}$ and a pore size of $500 \mu \mathrm{m}$ internally reinforced with a stainless-steel spiral stent. In all experiments, a canine mediastinal trachea 10 cartilage rings in length was resected, and the prosthesis was then implanted with an omental flap.

Results: Lower pore size and density $\left(300 \mu \mathrm{m}, 25\right.$ pores $\left./ \mathrm{cm}^{2}\right)$ led to essentially no tissue ingrowth. Larger pore size $(700 \mu \mathrm{m})$ and low density $\left(25\right.$ pores $\left./ \mathrm{cm}^{2}\right)$ led to rapid and excessive ingrowth of granulation. Midrange pore size $(500 \mu \mathrm{m})$ and high density $\left(100\right.$ pores $\left./ \mathrm{cm}^{2}\right)$ invited steady tissue ingrowth, but marked luminal stenosis eventually developed. Stent-reinforced prostheses with $500-\mu \mathrm{m}$ pores at 64 pores/ $\mathrm{cm}^{2}$, as used in the second set, maintained an average patency rate of $60 \%$ or more (range, 20\%-100\%) at least 12 months after implantation.

Conclusion: Our data show that porosity is a key factor for tissue growth through our Dacron tracheal prostheses. This artificial trachea model has led to long-term survivors up to 27 months after the operation and seems promising as a basic model for clinical tracheal repair.

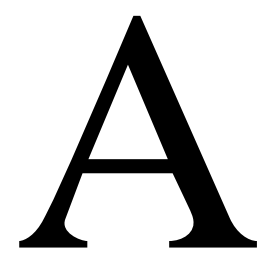

variety of tracheal prostheses have been reported, ${ }^{1}$ but an ideal model has to be refined for safe and durable practical use. The most common causes of graft failure include anastomotic stenosis, luminal stenosis, infection, dislocation, and migration.

Our laboratory has previously tested and reported a 5-cm-long nonporous type of artificial trachea made of a knitted Dacron tube that was internally coated with silicone except for $5 \mathrm{~mm}$ at each end, which was to be reserved for anastomoses. ${ }^{2-5} \mathrm{We}$ also tested the effects of hepatocyte growth factor and cultured fibroblasts to go with the abovementioned model to replace the mediastinal trachea in dogs. Although some of the dogs survived for more than a year after the operation in fair condition, anastomotic stenosis prevented most dogs from being long-term survivors.

On the other hand, from what had been reported by others, early tissue coverage and epithelialization of the internal surface of the graft is believed to prevent stenosis of the grafts in cases using porous-type artificial tracheas. Optimal graft porosity has been reported regarding other types of materials but not Dacron. This provided a motivation for us to test how porosity works in the Dacron tracheal graft models. This study is divided into 2 sections. The first set of experiments was designed to identify an optimal pore diameter and pore density to be used in a Dacron tube tracheal graft. The second aspect of this study focused on the application of the 

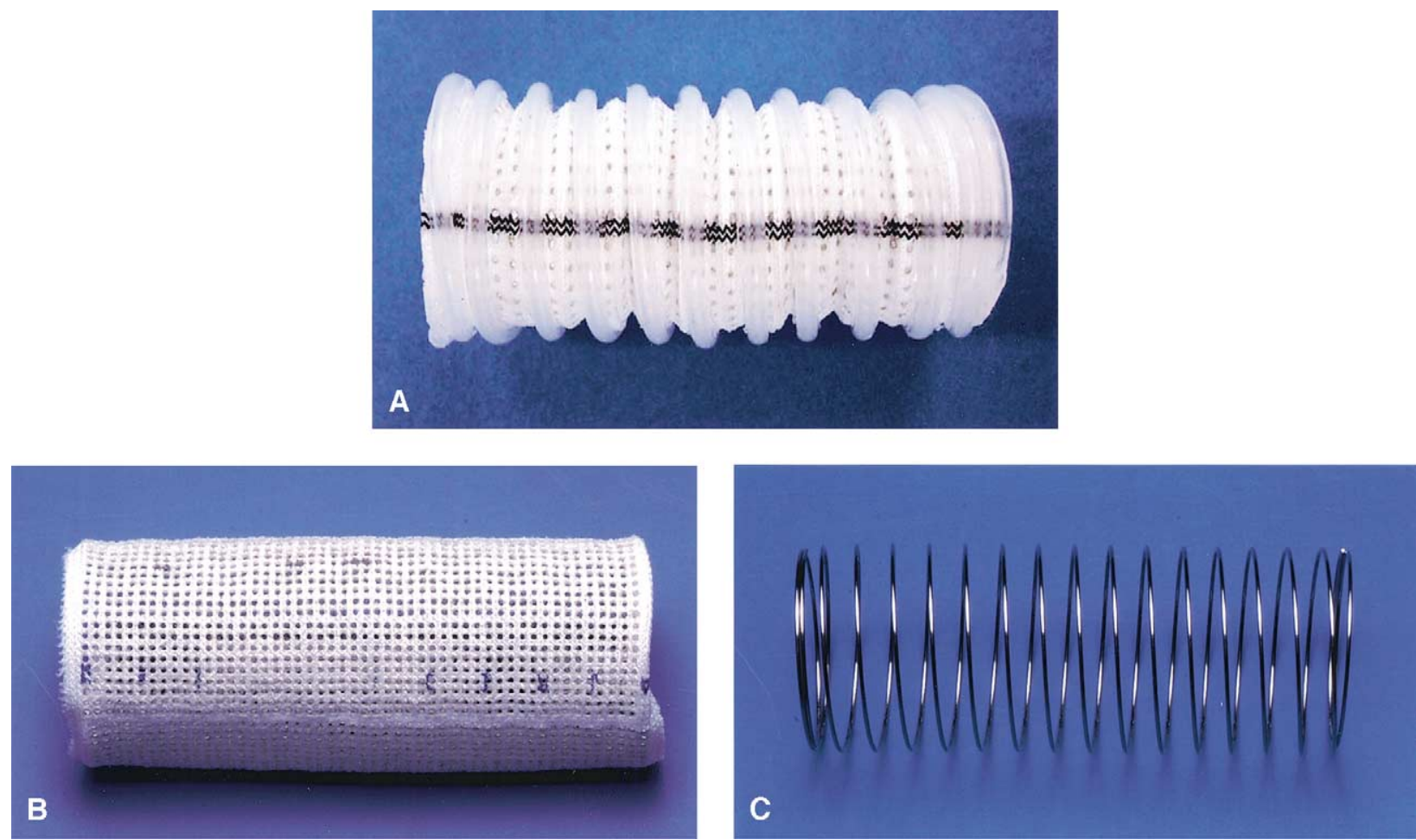

Figure 1. A, The Dacron tracheal prosthesis reinforced with heat-sealed silicone rings. $B$, The Dacron prosthesis with $500-\mu \mathrm{m}$ pores at a density of 64 pores $/ \mathrm{cm}^{2}$. C, Spiral stainless-steel stent inserted in the Dacron prosthesis.

optimal pore size and density thus obtained to our artificial tracheal model for replacement of the canine mediastinal trachea.

\section{Materials and Methods \\ Prosthesis}

A straight vascular prosthesis, $5 \mathrm{~cm}$ long and $16 \mathrm{~mm}$ in diameter, made of knitted external velour polyester (MICRON, Inter Vascular) was used with an internal mechanical support. Initial porosity of this material was $1200 \mathrm{~mL} \cdot \mathrm{cm}^{2} \cdot \min$. Pores were created in the structure by using a laser ablation technique. The first set of grafts served to determine the optimal pore size and density for conditioned tissue ingrowth. Pore sizes of 300, 500, or $700 \mu \mathrm{m}$ were generated with pore densities of either $25 / \mathrm{cm}^{2}$ or $100 / \mathrm{cm}^{2}$. Grafts were reinforced in this set with $1.5-\mathrm{mm}$ wide heat-sealable silicone rings (Figure 1, $A$ ). The second set of grafts were made with $500-\mu \mathrm{m}$ pores at a density of 64 pores $/ \mathrm{cm}^{2}$ but reinforced with a 0.4 -mm-diameter spiral stent made of stainless steel (Figure 1, $B$ and $C$ ). Pore density was set at 64 pores $/ \mathrm{cm}^{2}$ depending on the results of the first set of experiments and also for technical reasons, meaning a midrange density of between 25 and 100 pores $/ \mathrm{cm}^{2}$. Laser ablation technology, heat-sealable silicone, and stainless-steel spiral stents were obtained from Koken Co, Ltd. Each graft was finally coated with fibrin glue (Beriplast P, Aventis Behring) just before the operation to prevent air leakage.

\section{Implantation}

Fifteen mongrel dogs weighing 14 to $16 \mathrm{~kg}$ were anesthetized with pentobarbital sodium $(4 \mathrm{mg} / \mathrm{kg})$, intubated endotracheally, and administered GO by means of a ventilator (Mear/ADV-1000MK II, Senko Ika Kogyo). With each dog in the supine position, an upper median abdominal incision was made. An omental flap was prepared, including the right gastroepiploic artery. The abdomen was temporarily closed, and a right thoracotomy was performed through the fourth intercostal space, with the dog in the left lateral position. The mediastinal trachea was exposed and resected at a length of 10 cartilaginous rings, whereas the left lung was ventilated through the second endotracheal tube placed through the operative field (Figure 2).

The artificial tracheal graft was then implanted by using endto-end anastomoses with 4-0 nonabsorbable running sutures (Ethibond Excel, Ethicon). After the anastomoses were completed, the abdominal incision was reopened, with the dog kept in the lateral position. The previously made omental flap was introduced into the right chest cavity through a slit made in the right hemidiaphragm. The entire graft was then wrapped with the pedicled omental flap. The chest and abdominal wounds were finally closed in layers, and the thoracostomy tube was removed immediately after closing the wound.

Postoperatively, each dog was allowed to recover spontaneously. A 500-mg intramuscular dose of kanamycin was given on the day of operation and on postoperative day 1 . 

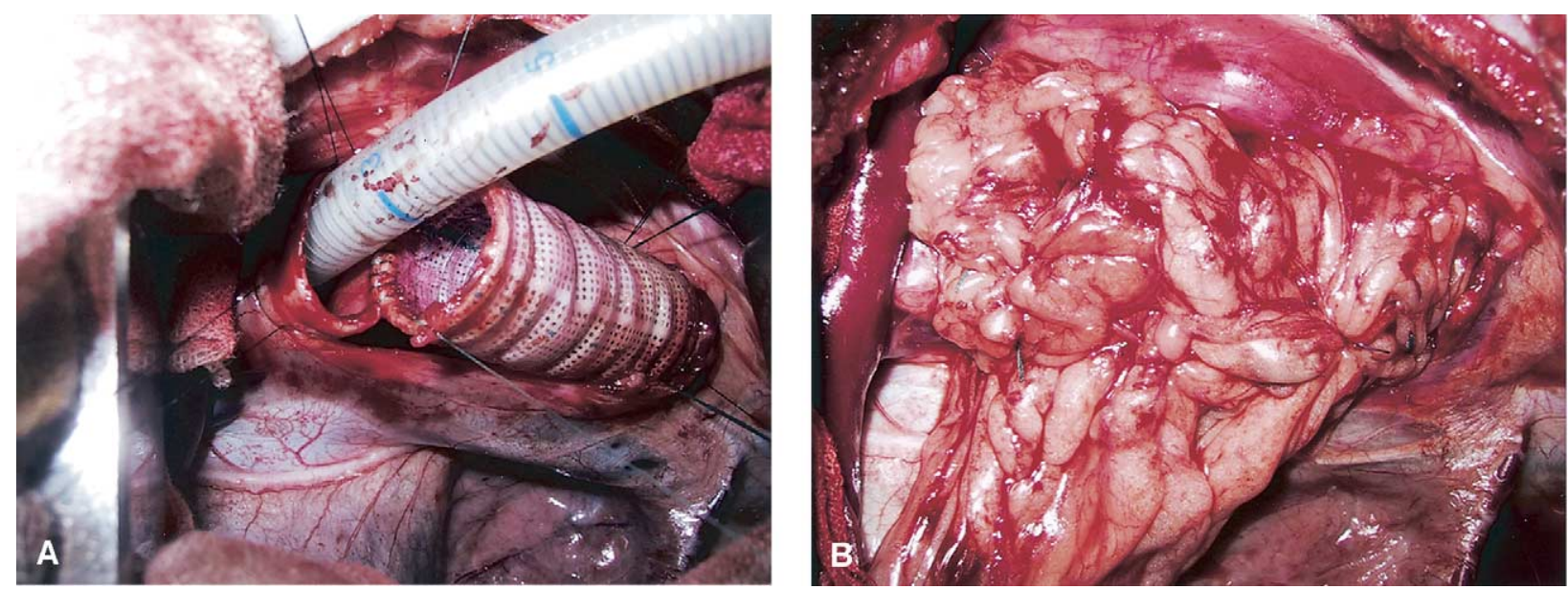

Figure 2. Implantation of the Dacron prosthesis in a dog. A, Caudal anastomosis was performed with a second endotracheal tube inserted through the operative field. B, The entire prosthesis was wrapped by the omental flap.


Figure 3. Bronchoscopic view of the reconstructed trachea. A, Ingrown tissue was limited by heat-sealed silicone rings in the preliminary experiment series. B, Good luminal patency and full-tissue coverage of the prosthesis were observed at 21 months after implantation in the second experimental series.

\section{Conventional Bronchoscopic and Histologic Examinations}

A bronchoscope (model BF1T30 or BF200, Olympus Optical Co Ltd) was applied at 2 weeks and every month thereafter during intravenous pentobarbital sodium anesthesia through an endotracheal tube. We observed the degree of tissue ingrowth and the patency rate of the graft, and we also histologically examined the degree of epithelialization on the internal surface of the ingrown tissue by means of punch biopsy. Biopsy specimens were fixed in $10 \%$ phosphate-buffered formalin, embedded in paraffin, and sectioned. Sections were stained with hematoxylin and eosin. The patency rate was calculated by dividing the internal cut surface area of the central portion of the graft by the native tracheal cut surface area on bronchoscopic views.

\section{Magnifying Bronchoscopic Examination}

A magnifying bronchoscope (XBF-200HM, Olympus Optical Co Ltd) was used to examine the internal surface of the graft at 12 to 27 months during intravenous pentobarbital sodium anesthesia through an endotracheal tube. Ingrown vessels within the tissue on the inner surface of the graft were observed in vivo, and magnified pictures were obtained. 
TABLE 1. Results of circumferential tracheal reconstruction with the Dacron prosthesis

\begin{tabular}{|c|c|c|c|c|c|c|c|}
\hline Dog no. & $\begin{array}{c}\text { Pore size } \\
(\mu \mathrm{m})\end{array}$ & $\begin{array}{c}\text { Pore density } \\
(\text { pores/cm²) }\end{array}$ & $\begin{array}{l}\text { Graft tissue } \\
\text { coverage }\end{array}$ & $\begin{array}{c}\text { Epithelial } \\
\text { Confirmation } \\
\text { (mo) }\end{array}$ & $\begin{array}{l}\text { Site of } \\
\text { stenosis }\end{array}$ & $\begin{array}{c}\text { Time after } \\
\text { Implantation } \\
\text { (mo) }\end{array}$ & Outcome \\
\hline 1 & 300 & 25 & None & None & Anastomosis & 15 & Killed \\
\hline 2 & 500 & 25 & Part & 0.5 & Anastomosis & 14 & Died \\
\hline 3 & 500 & 25 & Part & 0.5 & Luminal & 3 & Killed \\
\hline 4 & 500 & 100 & Entire at $1 \mathrm{mo}$ & 1 & Luminal & 2 & Killed \\
\hline 5 & 500 & 100 & Entire at $1 \mathrm{mo}$ & 1 & Anastomosis & 2 & Killed \\
\hline 6 & 700 & 25 & Part & 0.5 & Anastomosis & 5 & Killed \\
\hline 7 & 700 & 25 & Part & 2 & Anastomosis & 11 & Killed \\
\hline 8 & 700 & 25 & Part & 0.5 & Anastomosis & 26 & Killed \\
\hline 9 & 700 & 25 & Part & - & - & 3 days & Died (ileus) \\
\hline 10 & 500 & 64 & Part & None & None & 27 & Alive \\
\hline 11 & 500 & 64 & Entire at $1 \mathrm{mo}$ & 1 & Luminal & 20 & Killed \\
\hline 12 & 500 & 64 & Entire at $1 \mathrm{mo}$ & 2 & Luminal & 24 & Alive \\
\hline 13 & 500 & 64 & Entire at $2 \mathrm{mo}$ & None & Luminal & 24 & Alive \\
\hline 14 & 500 & 64 & Part & 12 & Luminal & 19 & Alive \\
\hline 15 & 500 & 64 & Entire at $3 \mathrm{mo}$ & 1 & Luminal & 17 & Alive \\
\hline
\end{tabular}

\section{Animal Care}

Animals were killed with an injected overdose of sodium pentobarbital if intraluminal patency rates, anastomotic patency rates, or both decreased to less than $10 \%$.

All animals received humane care in compliance with the "Principles of Laboratory Animals Care" formulated by the National Society for Medical Research and the "Guide for the Care and Use of Laboratory Animals" prepared by the National Academy of Science and published by the National Institutes of Health (publication no. 85-23, revised 1985).

\section{Results}

\section{Patency of the Implanted Grafts Seen by Means of} Conventional Bronchoscopic Examinations

Results are summarized in Table 1. All dogs tolerated the surgical procedure well, and perioperative mortality occurred only in dog 5, which died of ileus 3 days after the operation.

In the first set of experiments, it was seen that smaller pores $(300 \mu \mathrm{m})$ and lower density $\left(25\right.$ pores $\left./ \mathrm{cm}^{2}\right)$ led essentially to no tissue ingrowth, whereas larger pores (700 $\mu \mathrm{m})$ and low density $\left(25\right.$ pores $\left./ \mathrm{cm}^{2}\right)$ led to a rapid and excessive ingrowth of granulation tissue through the pores, with the ingrown tissue not uniformly covering the internal surface. Ingrowth was apparently disturbed at those pores incidentally occluded by the heat-sealed silicone rings (Figure $3, A)$. Although moderate pore size $(500 \mu \mathrm{m})$ and high density $\left(100\right.$ pores $/ \mathrm{cm}^{2}$ ) led to tissue ingrowth over the entire prosthesis, the lumen, however, exhibited marked stenosis by 2 months after the operation.

The second set of experiments was based on the results of the first set experiments. Pores $500 \mu \mathrm{m}$ in size with a density of 64 pores $/ \mathrm{cm}^{2}$ were expected to bring about a moderate amount but evenly distributed ingrowth on tissue on the inner surface of the grafts. Intraluminal patency rates of the grafts as of the second study are shown in Figure 4 with their time course. Dogs 10, 12, 13, 14, and 15 actually maintained an average patency rate at $60 \%$ or more (ranging from $20 \%-100 \%$ ) up to 12 months after implantation (Figure $3, B$ ). Conventional bronchoscopy revealed complete coverage of the inner surface of the graft with ingrown tissue by 3 months after implantation in 4 of 6 dogs.

Dog 10 has survived in a good condition without any remarkable stenosis of the graft for greater than 27 months after implantation. In dogs 10 and 14 conventional bronchoscopy revealed patchy areas left apparently uncovered by ingrown tissue on the inner surface of the graft 18 and 27 months after implantation, respectively, although no graft infection was seen.

\section{Histologic Examinations}

All dogs except dog 7 had the appearance of an epithelial cell lining on the inner surface, as confirmed on the basis of biopsy specimens taken from the ingrown tissue between 1 and 3 months after implantation (Figure 5, A). The graft harvested from dog 11 showed body stenosis by overgrowing whitish-colored tissue. This thick, almost scarring tissue also possessed an epithelial lining (Figure $5, B$ and $C$ ).

\section{Magnifying Bronchoscopic Examination}

A submucosal network of blood vessels was observed, extending from the native submucosal vessels across the anastomoses inward toward the inner surface of the graft for up to $1 \mathrm{~cm}$ in distance. These vessels ranged from 8 to 300 $\mu \mathrm{m}$ in diameter. In the central part of the prosthesis, vessels were observed coming through the pores, presumably originating in the omental flap. A fine, tiny vascular network was also observed, even in the area in which no ingrown 


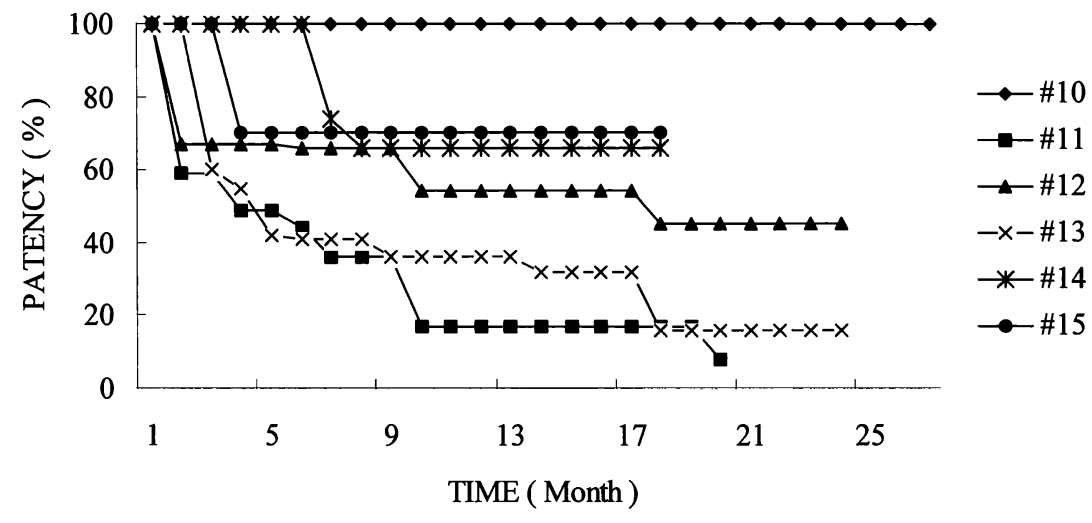

Figure 4. Intraluminal patency rates of the main experiment group.

tissue was observed by means of conventional bronchoscopy (Figure 6).

\section{Discussion}

Developing suitable materials and models for reconstructing the trachea has been an attractive area of thoracic surgery research for more than 50 years. A number of approaches to tracheal reconstruction have been reported. There have been autografts, ${ }^{6}$ allografts, ${ }^{7}$ xenografts, ${ }^{8}$ tissue-engineered grafts, ${ }^{9}$ grafts made of prosthetic materials, ${ }^{1}$ and combinations of these grafts. ${ }^{3-5}$ Each approach encountered limited success. We focused on prosthetic materials, aiming at easier clinical application.

Earlier in 1967, Graziano and associates ${ }^{10}$ reported on bifurcated semirigid synthetic polydimethyl siloxane grafts in canines. After this, Neville and associates ${ }^{11}$ evaluated a silicone nonporous-type prosthesis rimmed with Dacron in 62 clinical cases. Neville and coworkers ${ }^{12}$ observed that the prosthesis was rapidly incorporated into the surrounding tissue within the mediastinum but was unable to develop an epithelial bridging over the inner surface of the prosthesis. Neville and associates ${ }^{11}$ claimed that ciliated epithelial lining of the prosthesis was not essential.

Pearson and colleagues ${ }^{13}$ evaluated a heavy, porous Marlex mesh prosthesis and observed a thin layer of granulation tissue penetrating the graft through the pores within 6 weeks postoperatively. This model was abandoned because of frequent occurrence of innominate artery erosion in clinical use. In 1994, Okamura and associates ${ }^{14}$ evaluated the collagen-conjugated fine Marlex mesh prosthesis and observed epithelial lining on the prosthetic inner surface with good biocompability. This report evolved our hypothesis and led to the evaluation of our present porous model. We also believe that an earlier ingrowth of tissue along with epithelialization led to a successful tracheal graft.

In the present study we chose Dacron as the material because of its good tissue compatibility and widespread clinical use. The native porosity of Dacron, however, does not seem sufficient for inviting tissue ingrowth. There have been no studies with Dacron as a modified porous material for circumferential tracheobronchial reconstruction. Kai$\operatorname{ser}^{15}$ reported that a $2 \times 2-\mathrm{cm}$ defect of canine cervical trachea was closed with a Dacron patch having a porosity of 25 to $50 \mu \mathrm{m}$ or 125 to $150 \mu \mathrm{m}$. He observed that the smaller-pored Dacron patch was rejected, and the largerpored patch was covered by connective tissue as quickly as 90 days after the operation. Shimizu and associates ${ }^{16}$ reported an optimal pore size of fine Marlex mesh, approximately $300 \mu \mathrm{m}$, for a patch graft to the cervical trachea in dogs. Nelson and colleagues ${ }^{17}$ worked on bioelectric polyurethane and reported 60 - to $120-\mu \mathrm{m}$ pores as suitable for a mediastinal tracheal graft with an omental flap in dog models. Jorge and coworkers ${ }^{18}$ reported an optimal pore size of $30 \mu \mathrm{m}$ in an expanded polytetrafluoroethylene prosthesis reinforced with spiral silicone rings implanted to cervical circumferential defects in rabbit models. They observed 3 of 10 animals having intraluminal hypertrophic granulation tissue 1 month after the operation. The suitable pore size seems to vary greatly depending on the animal model, material, and prosthetic model used in relation to the surrounding host tissue. We concluded in this series that optimal pore size was $500 \mu \mathrm{m}$ along with a pore density of $64 / \mathrm{cm}^{2}$.

Rigidity of the prosthesis is another important issue. A tube made of wire mesh, Teflon, or silicone might maintain the patency to some extent by means of its own mechanical rigidity. Stiffer materials might tend to cause erosion of neighboring great vessels in the mediastinum. This complication is potentially avoidable by inserting a muscle flap or pericardial flap between the prosthesis and the vessels. Alternative soft material could not maintain an open airway. We first reinforced the porous Dacron prosthesis from the outside by heat sealing it with $1.5-\mathrm{mm}$ silicone rings in a spiral pattern. This worked well to prevent airway collapse 

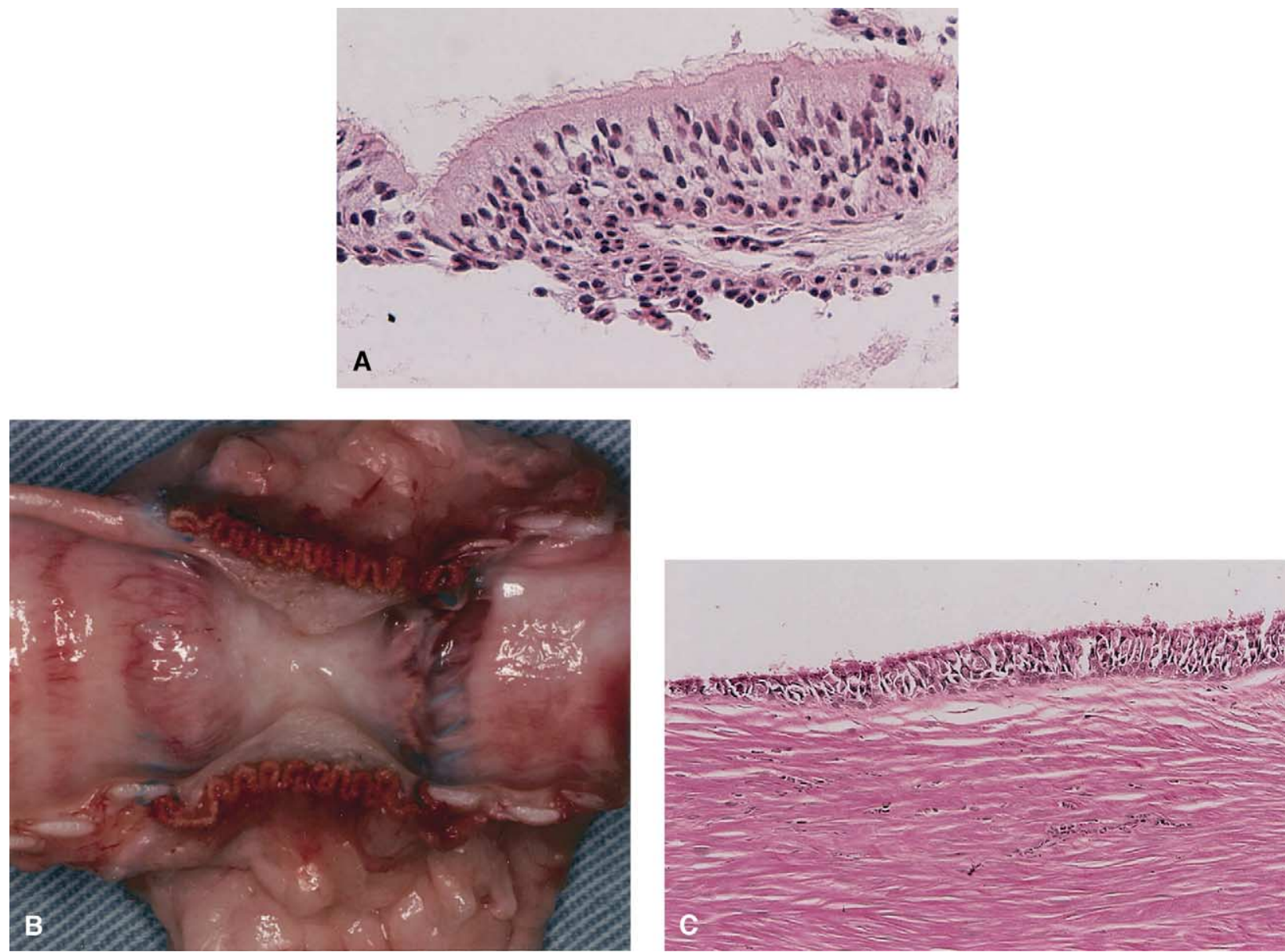

Figure 5. Histologic examination. A, A specimen taken from the internal tissue revealing ciliated cells at 1 month after the implantation. B, Longitudinal section of the prosthesis 21 months after the implantation: the luminal surface was covered by smooth thick white tissue. C, Ciliated epithelial cells lined on thick fibrous tissue.

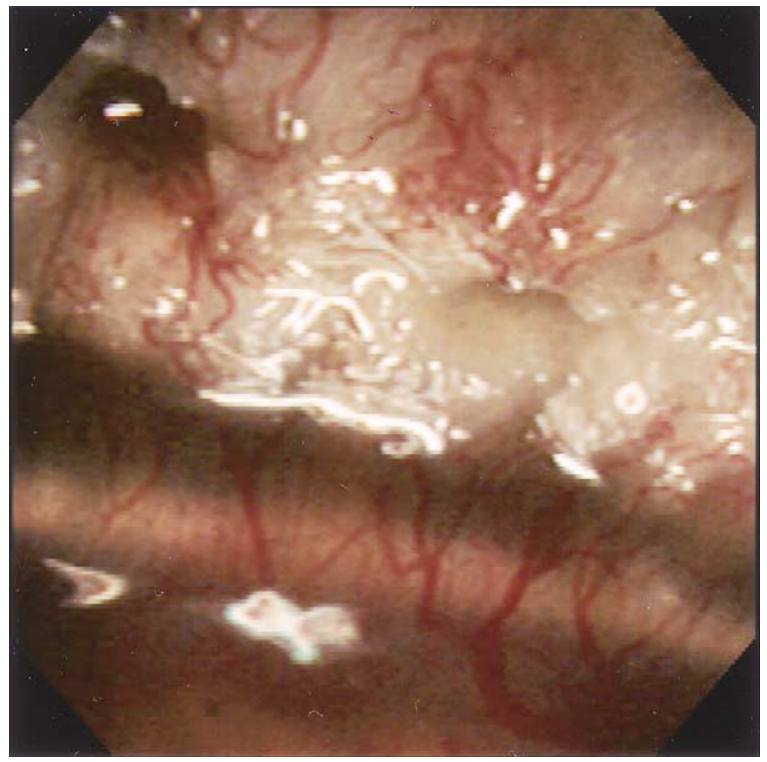

Figure 6. Magnifying bronchoscopic view revealing a fine vascular network on the Dacron prosthesis. but partially prevented tissue ingrowth. We therefore changed the stenting model to use a spiral stainless-steel stent applied from inside to prevent collapse. This stent did not obstruct the pores and led to rapid and relatively uniform tissue ingrowth. It should be mentioned that back in 1950, Belsey ${ }^{19}$ reported the first successful circumferential replacement of a human intrathoracic trachea. Belsey used a composite prosthesis with a steel spring covered with fascia lata. Surprisingly, the steel wire was completely covered with regenerated ciliated epithelium and completely embedded in the wall of the trachea 1 year after implantation. In the present study the stainless-steel stent also became embedded in the ingrown granulation tissue as early as 2 weeks after the operation. Dog 11 showed shortening in the length of the prosthesis caused by accordion-like prosthetic shrinkage, which subsequently caused luminal stenosis. The spiral configuration of the stent was therefore one of the causes of prosthetic stenosis. Further reinforcement or modification of the spiral stent would likely resolve this problem. 
We do believe that the lining epithelium came from both ends of the native trachea onto the inner surface of the graft. Epithelial lining on granulation tissue was present between 1 and 3 months after the operation. Pearson and associates ${ }^{13}$ reported that further proliferation of granulation tissue ceased along with the surface epithelialization after the operation. In our present series, however, an early intraluminal stenosis occurred in these 2 dogs as a result of excessive tissue ingrowth, despite epithelialization. Possibly a continuous foreign body reaction against Dacron had an edge on the conditioning function of the epithelial cells. This phenomenon raises a need to do further research.

The omentum has been recognized as clinically useful when applied to the intrathoracic structure, ${ }^{20}$ and the omentum is well known to have an immunologic protective ability. One of the most important functions of the omentum is releasing angiogenic factors. Angiogenic factors activate the milky-spot macrophages, causing new capillaries to sprout and invade the fibrous network. ${ }^{21}$ Zhang and coworkers $^{22}$ reported that the omentum demonstrated the highest vascular endothelial growth factor secretion rate, as well as the highest concentration of vascular endothelial growth factor protein of the various rat tissues and organs examined. The omentum seems to be the best wrapping for autologous tissue to prevent air leakage, as well as graft infection, and leads to early granulation tissue. Nelson and associates ${ }^{17}$ indeed reported a stable healing process of tracheal prostheses by using omental-wrapping techniques. Teramachi and coworkers ${ }^{23}$ reported plenty of vessels in the regenerated mucosa of a collagen-coated Marlex mesh tracheal prosthesis after omentoplasty 3 to 6 months after implantation. They speculated that the vessels declined after complete intraluminal epithelialization of the inner surface.

Neovascularity of the ingrown tissue is another important issue to discuss. Nelson and associates ${ }^{17}$ reported details of neovascularity in tracheal prostheses in the mediastinal trachea with omental flap in dog models by using the barium suspension angiographic ex vivo technique. Magnifying bronchoscopy is a new technology developed by Olympus Optical Co Ltd. This scope makes it possible to perform real-time in vivo observation of small-sized vessels greater than $8 \mu \mathrm{m}$ in diameter. Generally, artificial materials are a hotbed for infection in a living body, especially in the airway because it is directly exposed to the outer environment. Two of the dogs in our second set had large areas of their grafts apparently uncovered by any tissue, as determined with a conventional bronchoscope. Neither animal, however, became infected, even beyond 18 to 27 months. We observed, in these areas, a fine network of vessels through pores of Dacron prostheses in these apparently uncovered areas by using the magnifying bronchoscope. We believe that the presence of a vessel network with a thin layer of tissue was protecting the graft from infection.
It is widely recognized that native tissue is preferable in reconstructing the tracheobronchial tree. Recently, Kojima and associates ${ }^{9}$ have tried to produce a tracheal prosthesis model made of purely autologous cultured chondrocytes. They evaluated an autologous tissue-engineered trachea by replacing a $5-\mathrm{cm}$ defect of the sheep cervical trachea. The tissue-engineered trachea looked almost indistinguishable from native tissue. The histology of the tissue-engineered trachea and native trachea was also similar. Because of the lack of rigidity, however, that model has not been able to sustain patency for a long period. Animals died in 2 to 7 days as a result of malacia and stenosis. In addition, the time needed to generate a tissue-engineered trachea limits its applications for clinical use.

In conclusion, our data show that our Dacron tube with $500-\mu \mathrm{m}$ pores and a density of 64 pores $/ \mathrm{cm}^{2}$ worked well up to 27 months after the operation. Only one of 6 dogs had intraluminal stenosis at the body of the graft. Epithelialization with ciliated cells appeared 1 to 2 months after implantation. A fine vascular network was observed when examined with a magnifying bronchoscope, even in portions apparently uncovered, as determined with a conventional bronchoscope. This artificial trachea model has led to longterm survivors and seems promising as a basic model for the clinical setting of tracheal repair.

\section{References}

1. Neville WE. Prosthetic replacement of the trachea. In: Grillo HC, Eschapasse $\mathrm{H}$, editors. International trends in general surgery: major challenges, Vol 2. Philadelphia: WB Saunders; 1987. p. 138-46.

2. Taira Y. Preventive effects of flexible anastomotic margins of an artificial trachea upon the anastomotic stenosis due to growth of granulation tissue. J Jpn Soc Bronchol. 1993;15:233-41.

3. Osada H, Takeuchi S, Kojima K, Yamate N. The first step of experimental study on hybrid trachea: use of cultured fibroblasts with artificial matrix. J Cardiovasc Surg. 1994;35:165-8.

4. Takeuchi S. Artificial trachea hybridized with cultured fibroblastsexperiments on dogs. J Jpn Soc Bronchol. 1995;17:16-23.

5. Kojima K. Effect of hepatocyte growth factor (HGF) on induction of epithelial extension onto the inner surface of the anastomotic ends of a hybrid artificial trachea implanted in dogs. J Jpn Soc Bronchol. 1995;17:570-7.

6. Kato R, Onuki AS, Watanabe M, Hshizume T, Kawamura M, Kikuchi $\mathrm{K}$, et al. Tracheal reconstruction by esophageal interposition: an experimental study. Ann Thorac Surg. 1990;49:951-4.

7. Mukaida T, Shimizu N, Aoe M, Andou A, Date H, Okabe K, et al. Experimental study of tracheal allotransplantation with cryopreserved grafts. J Thorac Cardiovasc Surg. 1998;116:262-6.

8. Hashimoto M, Nakanishi R, Umesue M, Muranaka H, Hachida M, Yasumoto K. Feasibility of cryopreserved tracheal xenotransplants with the use of short-course immunosuppression. J Thorac Cardiovasc Surg. 2001;121:241-8.

9. Kojima K, Bonassar LJ, Roy AK, Vacanti CA, Cortiella J. Autologous tissue-engineered trachea with sheep nasal chondrocytes. J Thorac Cardiovasc Surg. 2002;123:1177-84

10. Graziano JL, Spinazzola A, Neville WE. Prosthetic replacement of the tracheal carina. Ann Thorac Surg. 1967;4:421-31.

11. Neville WE, Bolanowski PJP, Kotia GG. Clinical experience with the silicone tracheal prosthesis. J Thorac Cardiovasc Surg. 1990;99:604-13.

12. Neville WE, Bolanowski PJP, Soltanzadeh H. Prosthetic reconstruction of the trachea and carina. J Thorac Cardiovasc Surg. 1976;72: 525-38. 
13. Pearson FG, Henderson RD, Gross AE, Ginsberg RJ, Stone RM. The reconstruction of circumferential tracheal defects with a porous prosthesis. J Thorac Cardiovasc Surg. 1968;55:605-16.

14. Okamura N, Nakamura T, Natsume T, Tomihata K, Ikeda Y, Shimizu Y. Experimental study on a new tracheal prosthesis made from collagen-conjugated mesh. J Thorac Cardiovasc Surg. 1994;108:337-45.

15. Kaiser D. Alloplastic replacement of canine trachea with Dacron. Thorac Cardiovasc Surg. 1985;33:239-43.

16. Shimizu Y, Tamura K, Kato H, Teramatsu T, Hino T. Study on the artificial trachea using mesh. Jpn J Artif Organs. 1983;12:486-9.

17. Nelson RJ, Goldberg L, White RA, Shors E, Hirose FM. Neovascularity of a tracheal prosthesis/tissue complex. J Thorac Cardiovasc Surg. 1983;86:800-8.

18. Jorge RG, Ramos ASP, Guevara ACL, Huedo M, Vega MG, Romeu FP. Experimental study of a new porous tracheal prosthesis. Ann Thorac Surg. 1990;50:281-7.
19. Belsey R. Resection and reconstruction of the intrathoracic trachea. Br J Surg. 1950;30:200-5.

20. Mathisen DJ, Grillo HC, Vlahakes GJ, Dagett WM. The omentum in the management of complicated cardiothoracic problems. J Thorac Cardiovasc Surg. 1988;95:677-84.

21. Liebermann-Meffet D. The greater omentum. Surg Clin North Am. 2000;80:276-93.

22. Zhang QX, Magovern CJ, Mack CA, Budenbender KT, Ko BSW, Rosengart TK. Vascular endothelial growth factor is the major angiogenic factor in omentum: mechanism of the omentum-mediated angiogenesis. J Surg Res. 1997;67:147-54.

23. Teramachi M, Okamura N, Yamamoto Y, Kiyotani T, Takimoto Y, Matsuda S, et al. Intrathoracic tracheal reconstruction with a collagenconjugated prosthesis: evaluation of the efficacy of omental wrapping. J Thorac Cardiovasc Surg. 1997;113:701-11. 